\title{
A IMPORTÂNCIA DO DESIGN PARA TORNAR AS REDES SOCIAIS MAIS INTERATIVAS
}

\author{
Bruno César Soares Santos/Centro Universitário UNA
}

\begin{abstract}
RESUMO: A concepção do design é uma das etapas mais importantes da construção de websites, por ordenar as informações e os componentes visuais das páginas de forma a articular um sistema de eficiente e fácil utilização. No caso das Redes Sociais On-line, que são sites com a proposta de promover a interação social e favorecer a comunicação entre usuários em vários contextos (pessoais, profissionais ou mais específicos), o design deve ser concebido levando-se em conta alguns conceitos e necessidades peculiares. Garantir usabilidade na relação pessoa x máquina e interação entre os seus usuários são necessidades que só serão supridas por meio de uma interface construída pensando-se na experiência de quem utilizará a rede, tarefa que cabe ao designer. Este artigo investiga a importância do design de interação com foco em usabilidade, no cumprimento da tarefa descrita anteriormente, e apresenta o case do uso do design no Facebook, a rede social mais acessada do mundo. Como complemento, o estudo pontua algumas inconsistências e necessidades latentes no design dos sites de redes sociais e lista os pontos positivos e potencialidades que eles apresentam.
\end{abstract}

PALAVRAS-CHAVE: Redes sociais. Design de interação. Usabilidade. Facebook. User experience.

\begin{abstract}
The design concept is one of the most important stages of building websites for ordering information and the visual components of the pages that are in order to articulate a system in an efficient and easy way to use. In the case of online social networks, which are sites with the proposal to promote social interaction and encourage communication between users in multiple contexts (personal, professional or more specific), the design should be developed taking into account some concepts and peculiar needs. Ensuring usability in the relationship person $\mathrm{x}$ machine and interaction between users of it are needs that can only be supplied by an interface built considering the experience of those who will use the network, this a task of designer. This paper examines the importance of interaction design focused on usability, in the accomplishment of the task described above and presents case of design use on Facebook, the most visited social network site of the world. As a complement, this study points out some inconsistencies and latent needs in the design of social networking sites and list the positives and potentialities they present.
\end{abstract}

KEYWORDS: Social networks, interaction design, usability, Facebook, user experience. 


\section{INTRODUÇÃO}

As redes sociais constituem um fenômeno da web que já integra o cotidiano da maioria das pessoas que usam frequentemente a Internet. Segundo estimativas da empresa especializada em informações de mercado, Nielsen (2011), até o ano de 2011, quase 4 (quatro) em cada 5 (cinco) usuários ativos de Internet visitariam redes sociais e blogs, e, em 2020, serão mais de 5 (cinco) bilhões de usuários de Internet em todo o mundo, e, desse total, 70\% estarão em redes sociais, interagindo ainda mais com amigos, marcas e produtos.

As redes sociais são dinâmicas e se modificam com o passar do tempo e a participação de seus usuários, quando não ficam estagnadas e acabam abandonadas. Esses usuários, por sua vez, representam o agente principal, que é responsável pela interação, criação e movimentação de conteúdos nas redes. Para tal, exige-se um ambiente que propicie a utilização das ferramentas do sistema com facilidade e, ao mesmo tempo, reproduza um espaço familiar e agradável. Nesse contexto, o design tem papel preponderante, por "se apropriar do comportamento social para propor novos modos de relacionamento" (VAN AMSTEL, 2011, p. 5), construindo interfaces capazes de articular a interação usuário x usuário e usuário x sistema. O presente artigo se insere nessa área de estudo, tendo como tema a análise do design como ferramenta para construção e otimização das redes sociais on-line.

Essa abordagem é relevante, uma vez que, por meio do fortalecimento dos estudos sobre design, usabilidade e redes sociais, torna-se possível construir uma base teórica robusta o suficiente para propor diretrizes para a utilização do design de forma consciente, visando à criação e à otimização de redes sociais adequadas ao cenário em que estão inseridas e ao seu público-alvo.

Assim, este artigo objetiva colaborar com o desenvolvimento de estratégias que visem ao melhoramento dos aspectos acima relacionados, e, para tanto, estudos anteriores sobre redes sociais e design de interação foram utilizados com heurísticas de análise para a web, visando elencar os exemplos de sucesso e levantar necessidades a serem supridas e potencialidades a serem exploradas. Utilizando uma abordagem baseada na ótica da usabilidade e com foco no usuário, pretende-se mostrar como o design pode oferecer às redes sociais uma ferramenta de construção da inteligência cognitiva ${ }^{\mathrm{i}}$, comparando as possibilidades com o que já é oferecido.

\section{REDES SOCIAIS: O FENÔMENO DO RELACIONAMENTO ON-LINE}

O ser humano tem, por natureza, necessidade de estabelecer redes de relacionamento, variando desde as famílias até contatos profissionais e de lazer. Na era digital, essa característica foi transferida para a Internet com a criação de redes sociais on-line, que viabilizam um contato ainda mais rápido e abrangente entre as pessoas, justificando, em parte, seu sucesso e rápida expansão.

Uma rede social é um grupo de pessoas que têm algum nível de relação ou interesse mútuo. Na Internet, elas começaram com a definição de “relationship site" (sites de relacionamento); hoje são conhecidas como redes sociais, ou ainda mídias sociais. Este último conceito, devido às suas características híbridas, gerou certa confusão sobre o que seria rede social e o que seria mídia social.

As redes sociais "buscam conectar pessoas e proporcionar sua comunicação e, portanto, 
podem ser utilizadas para forjar laços sociais” (RECUERO, 2004, p. 7). Alguns autores apresentam definições distintas sobre redes sociais on-line, mas, em linhas gerais, elas são ferramentas que permitem a interação social por meio da criação colaborativa e do compartilhamento de informação em formatos variados. Outra definição para o tema é:

\begin{abstract}
Também já chamado de "new media” (novas mídias), agora é conhecido como mídias sociais, que antes se referia ao poder de difundir uma mensagem de forma descentralizada dos grandes meios de comunicação de massa, agora é traduzido por muitos como ferramentas online que são usadas para divulgar conteúdo ao mesmo tempo em que permitem alguma relação com outras pessoas. (...) Então estas seriam ferramentas que têm como objetivo o compartilhamento de conteúdo, sendo as relações o segundo plano (ALTERMANN, 2010).
\end{abstract}

Visualmente, as redes sociais on-line podem ser representadas por grafos (conforme a Figura 1, abaixo) em que os nodos são os atores e as arestas são os relacionamentos entre eles. Pensando na dinâmica de uso, Mislov et al. (2007) afirma que é essencial que uma rede social tenha usuários, possibilite a criação de links entre eles e permita a segmentação desses links por interesses comuns dos usuários. Ela deve permitir a criação de um perfil (semi)público e a articulação de uma lista de usuários com quem é possível compartilhar uma conexão (BOYD; ELLISON, 2007). Deve permitir a representação digital das conexões dos usuários, sendo elas estabelecidas da solicitação ou de aceitação de requisições feitas por amigos ou outros contatos (ELLISON et al., 2009). Além dos itens obrigatórios, aplicativos e games representam um fator relevante na popularização das redes, devido ao crescente uso de dispositivos móveis e ao sucesso dos games sociais. Cabe ressaltar que as redes sociais têm 2 (duas) características importantes: seu alto grau de personalização e sua possibilidade de segmentação. Dessa maneira, as redes podem ser utilizadas para diversos fins, desde empresariais a pessoais, permitindo que o usuário as selecione, adapte e utilize da forma que lhe for mais confortável.

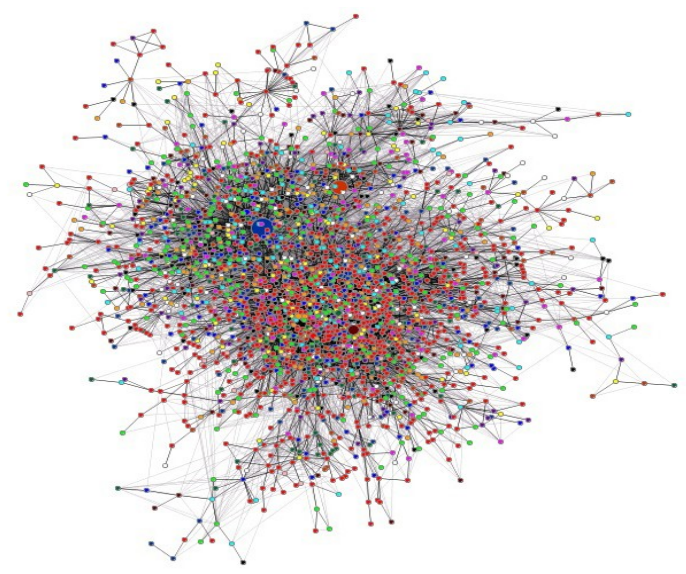

Figura 1: Grafos formados pelos elos de uma rede social.

Fonte: Raquel Recuero (2008) ${ }^{\mathrm{ii}}$

Segundo afirmam SANTANA et al. (2009), as redes sociais on-line se dividem em genéricas e especializadas. As genéricas seriam aquelas que aceitam diversos tipos de conteúdos textuais e multimídia, permitindo que os usuários interajam com esses conteúdos por meio de diversas funcionalidades, de maneira informal e "recreativa”. 


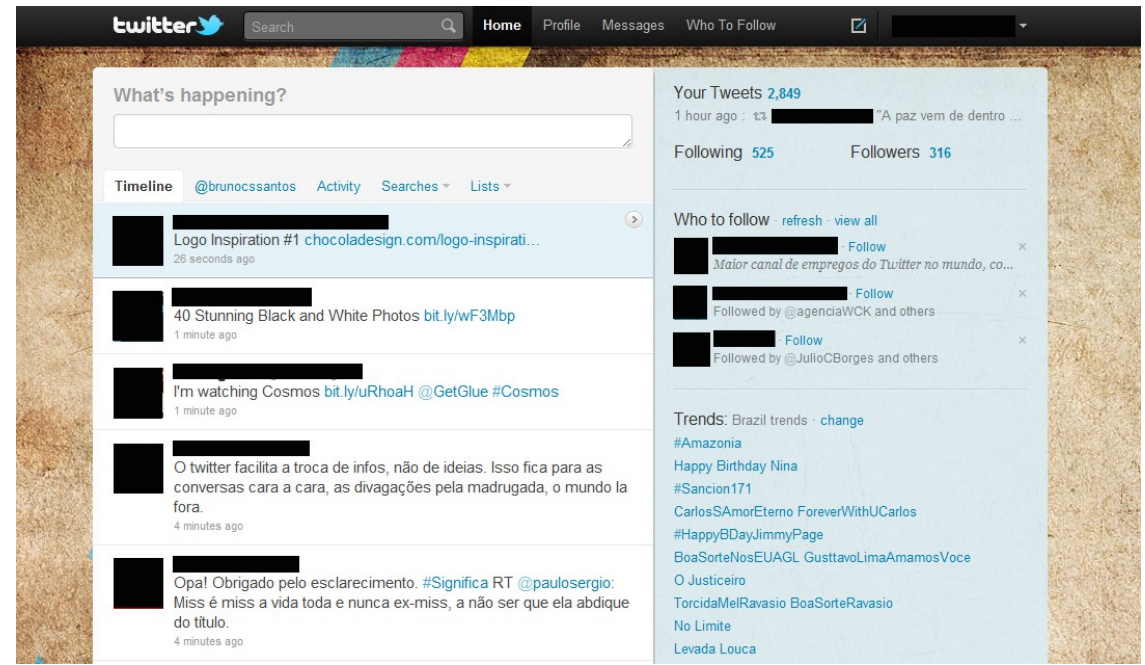

Figura 2: O Twitter é um exemplo de rede social genérica.

Fonte: Twitter (2012) ${ }^{\mathrm{iii}}$

Já as especializadas têm suas ferramentas focadas especificamente num trabalho e atendem a um determinado segmento de usuários. Podem tratar de uma temática específica, mas isso não se configura como obrigatoriedade.

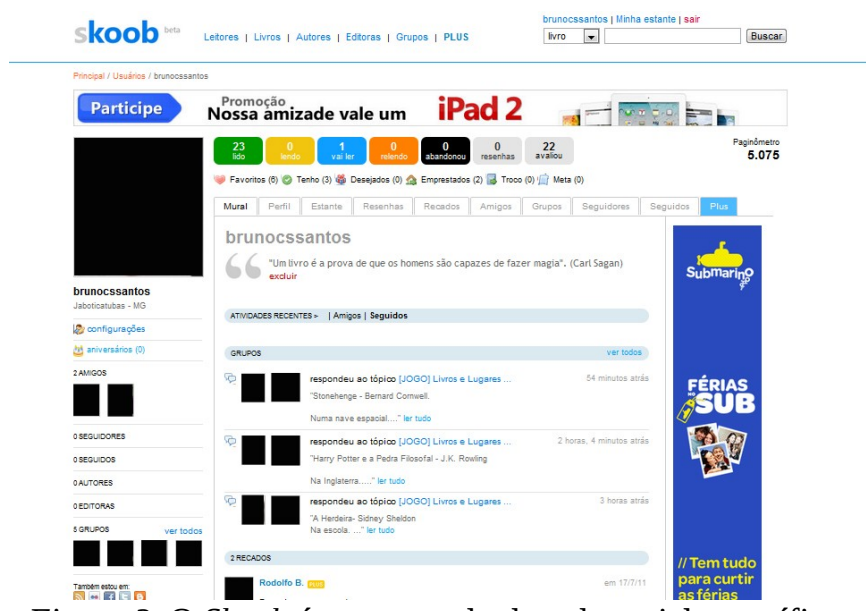

Figura 3: O Skoob é um exemplo de rede social específica.

Fonte: Skoob (2012) $)^{\text {iv }}$

O contexto em que se deu o surgimento e expansão das redes sociais é permeado por 3 (três) conceitos que são importantes para a compreensão desse fenômeno: calda longa, produção social e inteligência coletiva ${ }^{v}$.

O esvaziamento da cultura de massa ${ }^{\text {vi }}$ e o fortalecimento da cultura da calda longa ${ }^{\text {vii }}$

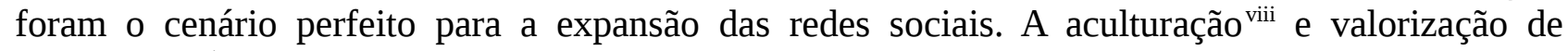
blockbusters $^{i x}$ e dos produtos considerados hits perderam espaço a partir do momento em que os mercados de nicho passaram a se fortalecer, tendo como característica a personalização dos produtos de acordo com o gosto do consumidor. Dessa forma, os meios digitais apareceram como ferramenta importantíssima para produção, distribuição e consumo de produtos, gerando 
abundância de opções. É nessa cultura de nichos que as redes sociais emergiram como um dos mais relevantes fenômenos de uma nova cultura digital.

Já se sabe que a sociedade contemporânea - também chamada de “sociedade em rede” sofreu mudanças significativas devido à massificação do uso da Internet (SANTANA et al., 2010), e que, entre essas mudanças, está a possibilidade de produção de conteúdos que podem ser disponibilizados na web. Sendo assim, a produção social aparece como resultado de uma economia pautada em informação, cultura e símbolos, que tem a Internet como principal ferramenta. Nas redes sociais, um número cada vez maior de produtores de conteúdos encontra espaço para compartilhar o conhecimento que desenvolve, horizontalizando, cada vez mais, as fontes de informação. Esse conhecimento gerado e compartilhado em comunidade, que se desenvolve e passa por uma curadoria em tempo real, por meio da mobilização de indivíduos de várias competências, origina uma inteligência coletiva, enraizada nas redes sociais.

Feita essa breve contextualização sobre redes sociais, este estudo parte para uma avaliação mais profunda de um ponto crucial relacionado a elas, que é o design centrado na usabilidade, para levantar hipóteses de como ele pode facilitar a interação do usuário e tornar uma rede mais eficiente e apreciada. Os próximos pontos a serem apresentados são o design de interação e o conceito de usabilidade.

\section{DESIGN DE INTERAÇÃO: USABILIDADE COMO FOCO CENTRAL}

O design de interação tem sua abordagem centrada no usuário e preocupa-se com o desenvolvimento do produto. Para Arnold (2010), sua preocupação central é "projetar produtos interativos que sejam de fácil aprendizagem, eficazes no uso e capazes de proporcionar ao usuário uma experiência gratificante”. Essas características nortearam sua escolha como ferramenta de análise da eficácia de uma rede social, neste estudo.

Ao se realizar um projeto de um produto interativo, as exigências básicas são: saber bem como é o usuário, de que maneira ele utilizará o produto e em quais circunstâncias (onde e quando) ocorrerá sua utilização. O designer de interação se ocupa de realizar esses questionamentos e estipular parâmetros para que o produto final forneça "suporte às atividades cotidianas das pessoas” (PREECE, ROGERS e SHARP, 2005, p. 28), atendendo, ao máximo, as expectativas de quem o consumir, pois seu sucesso dependerá de uma leitura precisa das necessidades do usuário.

Apesar de existir um profissional especializado para a área, uma equipe dedicada ao desenvolvimento com foco em usabilidade não pode ser composta apenas por um tipo de profissional. Isso se deve à multidisciplinaridade, uma das características do design de interação, que se destaca por buscar o entendimento das atitudes e reações dos usuários finais dos produtos sob a ótica de mais de uma área de atuação. A utilização de especialidades diferentes (Psicologia, Engenharia, Informática, etc.) em um mesmo projeto traz interpretações diversas sobre o que está sendo desenvolvido, aumentando a quantidade de ideias, métodos e soluções criativas para o projeto.

Outros pontos cruciais do design de interação são o processo e as metas. No que diz respeito ao processo, Preece, Rogers \& Sharp (2005) apontam as 5 (cinco) atividades abaixo como sendo básicas no design de interação e necessariamente "complementares e repetidas constantemente”. São elas: 
- identificar necessidades;

- $\quad$ propor soluções para o problema;

- desenvolver designs alternativos ao preexistente e que preencham as necessidades do item anterior;

- construir protótipos interativos dos designs propostos, para análise; e

- avaliar o que está sendo construído durante o seu desenvolvimento.

O design de interação não é um conceito e, dessa forma, só é bom se relacionado "à filosofia do design centrado no usuário” (ARNOLD, 2010), em que o público final do produto é ouvido em todo o seu desenvolvimento. Sendo assim, durante e depois dessas 5 (cinco) etapas, devem ser realizadas avaliações constantes com o usuário, por meio de "observação, conversa, entrevistas, testes de desempenho na realização de tarefas, aplicação de questionário, além de diversas outras formas de testes” (ARNOLD, 2010). Terminadas as avaliações, são definidos os pontos fortes e fracos do projeto, para que a equipe trabalhe em cima deles.

Todo o processo deve ser norteado por metas, que num projeto de design de interação se dividem em dois grupos: as de usabilidade e as de experiência do usuário. As que se referem à usabilidade pretendem preencher critérios que facilitem tanto o trabalho dos designers e desenvolvedores, quanto a utilização do produto pelo usuário. São elas: eficácia, eficiência, segurança, utilidade, learnability (capacidade de aprendizado) e memorability (capacidade de memorização). Já as que tratam da experiência do usuário surgiram da necessidade de metas que, ao mesmo tempo, focassem na melhoria da eficiência e produtividade no trabalho e se preocupassem em criar o que Arnold (2010) chamou de "sistemas satisfatórios, agradáveis, divertidos, interessantes, úteis, motivadores, esteticamente apreciáveis, incentivadores de criatividade, compensadores e emocionalmente adequados". Por fim, os 2 (dois) tipos de metas, quando analisados e combinados de forma consciente, podem garantir que os produtos proporcionarão aos usuários uma experiência que os fará se sentirem bem no decorrer da interação, posto que:

\footnotetext{
Um software pode ser classificado como sendo de boa usabilidade quando os seus usuários aprendem a utilizá-lo com facilidade (learnability), se lembram facilmente de tarefas anteriormente já realizadas (memorability), ou quando consegue associar padrões entre as diversas telas de um mesmo sistema, através da ordem de disposição dos itens, rapidez no desenvolvimento de tarefas, o que leva à conclusão lógica de que a manipulação do software é bastante fácil e que por sua vez, essa facilidade eleve a produtividade do usuário (OLIVEIRA, 2009, p. 38).
}

Os 2 (dois) últimos fatores a serem destacados na área do design de interação são os princípios e as heurísticas. Os princípios básicos do design são conhecimentos que orientam, sem padrões rígidos, o que deve ou não ser feito no trabalho dos designers, levando em consideração desde teorias até o senso comum. Os mais utilizados são os listados abaixo, estipulados por Don Norman (2006): 
- Visibilidade - As funções do sistema deixam claro aos usuários o que eles devem fazer?

- Feedback - Que retorno o usuário recebe após suas ações?

- Restrições - Como estão sinalizadas, para o usuário, as áreas e funções que ele pode utilizar e quais estão desativadas?

- Mapeamento - Existe uma relação lógica entre os controles e seus efeitos?

- Consistência - As interfaces foram projetadas para que seus elementos realizem operações comuns entre si?

- Affordance - O produto tem uma característica que permite às pessoas saber como usá-lo?

Os princípios são teóricos e, quando postos em prática, dão origem às heurísticas, que são as interpretações dos princípios do design de interação por meio de experiências práticas. Elas podem levar em conta critérios como a análise da ergonomia do produto ou da disposição de informação, sendo estipuladas de acordo com a questão analisada. No caso do produto analisado neste artigo, uma página web, a avaliação heurística da usabilidade do projeto em desenvolvimento orienta a construção de um projeto realmente interativo e eficiente, que permita detectar erros importantes ainda em tempo de serem corrigidos. São exemplos de modelos de heurísticas para análise da web, as propostas por Nielsen (2009) e as apresentadas por Dias (2007), as últimas mais focadas em portais corporativos.

Tendo essa breve compreensão acerca do que é o design de interação, o próximo passo é compreender como ele pode ser aplicado às redes sociais e mensurar a importância que ele tem para a eficiência de uma rede.

\section{O FACEBOOK E A UTILIZAÇÃO DO DESIGN COMO FERRAMENTA DE INTERAÇÃO NAS SOCIETAL INTERFACES}

Existe um número exponencial de sites de redes sociais, desde as mais genéricas às mais específicas, mas poucas alcançaram o status de destaque do Facebook, criado por Mark Zuckerberg e um grupo de estudantes da Universidade de Harvard, nos Estados Unidos. Em 2004, quando o site entrou no ar, o MySpace era a rede social mais acessada e não havia prognósticos do que o Facebook viria a se tornar. Hoje, mesmo com grande concorrência - em especial do Google+, da rival Google - ele já é, segundo dados do portal de produção e compartilhamento de conteúdo, BuzzFeed, o site mais acessado da internet ${ }^{\mathrm{x}}$, com 1,1 bilhão de visitantes mensais.

Tais resultados são frutos de uma estratégia bem elaborada, em que o design é tido como parte importante para viabilizar as relações humanas por meio de uma interface que as tornem o mais naturais possível. Tal preocupação parte de premissa de que a experiência do usuário com 
uma rede social deve ser a melhor possível, para que ela transmita as sensações de eficiência e satisfação. Entretanto, agradar ao usuário no ambiente web não é uma tarefa que tenha uma receita infalível.

Assim como os produtos digitais sofreram evolução, o mesmo aconteceu com o design, que teve de perceber as necessidades que surgiram e a nova forma de pensar dos usuários. A natureza da interação do homem com o computador mudou drasticamente, com a inserção de novos artefatos que cada vez mais ocupam o espaço do desktop no cotidiano. Mesmo sem parâmetros fixos, alterações significativas já são notadas, motivadas por fatores como a mobilidade (novos locais e formas de uso, a diminuição da distinção de trabalho e vida particular, etc.) e o compartilhamento em rede (declínio dos documentos individuais).

Essa mudança de perspectiva fica evidenciada nos estudos de IHC (Interação HomemComputador), uma matéria interdisciplinar que trabalha com diversas especialidades para analisar a relação homem e máquina. Ela se dividiu, inicialmente, em 2 (duas) ondas de comportamento em que, segundo Baranauskas et al. (2008), o papel da pessoa passou de "indivíduo passivo, fragmentado, despersonalizado e desmotivado", na primeira, para "indivíduo ativo e no controle da situação", na segunda. Já as características descritas no parágrafo anterior inserem as novas interações numa terceira onda, uma evolução da segunda, em que as novas tecnologias, portáteis e móveis, passam a ocupar a vida pessoal dos indivíduos e não apenas o ambiente de trabalho:

Conceitualmente, a terceira onda de IHC tem foco em aspectos culturais representados por fatores estéticos (Bertelsen, 2006), expansão de fatores cognitivos aos emocionais (Norman, 2002, 2004) e fatores pragmático-sociais da experiência (McCarthy e Wright, 2004). Na terceira onda a tecnologia extrapola os limites do contexto de trabalho para estar nas casas das pessoas, em suas vidas e cultura (BARANAUSKAS et al., 2008).

Toda essa nova conjuntura deve ser absorvida e compreendida, para que o design possa acompanhar as tendências e necessidades apresentadas nessa terceira onda, sem se tornar obsoleto e pouco eficiente. Nesse contexto, vem se solidificando o conceito de societal interfaces, que seriam interfaces que contemplariam a interação entre pessoas e não entre pessoas e máquinas:

Uma interface social é um ponto crítico de interseção entre modos de vida diferentes, campos sociais ou níveis de organização social, onde descontinuidades sociais baseadas em diferenças de valores, interesse, conceitos e poder, são mais susceptíveis de serem localizadas (LONG, 2001).

As redes sociais são exemplos de societal interfaces, em que os estudos de usabilidade apresentados anteriormente devem direcionar o design para a construção de uma interface mais humanizada, na qual as pessoas se percebam cada vez menos em contato com o computador e cada vez mais em contato com outros usuários em rede.

Do ponto de vista técnico das interfaces, o design tem, então, de garantir que uma rede social seja eficiente quanto à usabilidade (relação com a máquina) e humana na interação (conexão pessoa/pessoa). Deve oferecer um produto aberto, passível de aprimoramentos, e respeitar o contexto de sociedade colaborativa em que está inserido.

Esse embasamento é importante para a análise do case de utilização de design pelo Facebook, com foco no equilíbrio entre estética e usabilidade do sistema, seus pontos positivos e 
negativos. A escolha do Facebook segue os critérios de "maior tráfego de acesso" e "diversidade de uso”, propostos por Baranauskas et al. (2008), além da sua característica de rede social genérica. Os critérios de análise se baseiam nas heurísticas para análise de sites propostas por Nielsen (2001), apresentadas como princípios fundamentais da usabilidade.

De início, a abordagem destaca as questões referentes à liberdade e ao controle por parte do usuário. A eficiência de uma rede social passa necessariamente pela usabilidade, o que exige que ela desenvolva um sistema que garanta aos usuários caminhos fáceis e de visualização clara, para localizar ambientes e sair de lugares inesperados em que ele se encontre.

No Facebook, o usuário tem, na maioria das vezes, controle suficiente para abortar tarefas ou voltar ao estado anterior, em caso de desistência de alguma ação, como acontece no exemplo dos ícones de remoção, presentes em todas as postagens, e na permissão para edição de comentários já publicados, recentemente implementada. Entretanto, tal rede social ainda falha por não oferecer essa possibilidade de edição em caso de postagens só de texto ou de frases escritas em compartilhamentos de vídeos.

Complementando esse raciocínio, o sistema precisa assegurar a visibilidade do seu status, oferecendo feedback constante ao usuário sobre o que está acontecendo. Nesse ponto, o Facebook é eficiente, por dar respostas breves e, por meio da sua arquitetura de informação, direcionar as informações da forma mais linear e esclarecedora, como ocorre no campo de mensagens e de convites para eventos, que permite leitura e gerenciamento rápidos, sendo que, no primeiro caso, o usuário acessa inclusive mensagens mais antigas. Por outro lado, ele peca na lista de atualizações da conta desse mesmo usuário, por não lhe oferecer um controle sobre a quantidade de atualizações visíveis, mas sim, um número estipulado pelo próprio sistema.

Com relação a nomenclaturas, os sites de redes sociais devem ser compatíveis com o mundo real e ter padrões consistentes e claros. Para isso, neles devem-se usar palavras, conceitos e frases comuns, evitando-se termos muito técnicos relacionados ao software. Os padrões adotados devem evitar que os usuários precisem pensar se palavras, situações ou ações distintas significam a mesma coisa.

Uma das mais marcantes implementações do Facebook prima pela simplicidade. O mais popular dos seus botões, o "curtir”, é exemplo claro de aplicação da heurística citada no parágrafo anterior. Além de seguir a filosofia minimalista do design do site, o "like" é um termo óbvio, elegante e fácil de entender, o que o torna uma solução adequada para qualquer tipo de usuário, conforme pode ser notado na Figura 4: 


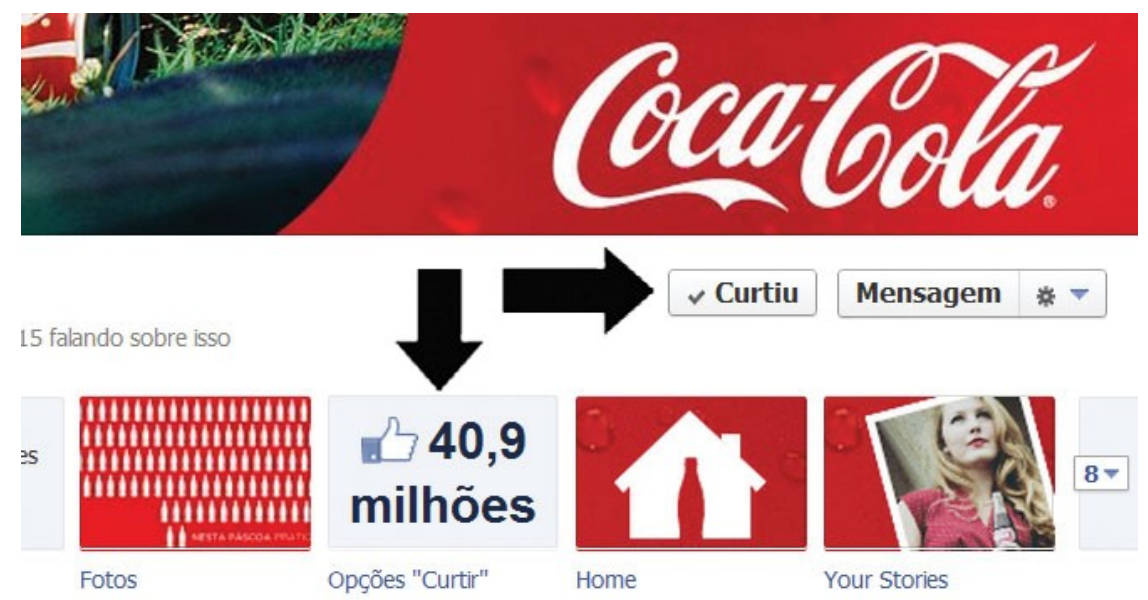

Figura 4: Botão “curtir” de uma página do Facebook Fonte: Facebook (2012) $)^{\mathrm{xi}}$

O Facebook contém algumas inconsistências, principalmente no que diz respeito à localização de certas ferramentas de gerenciamento, como o bloqueio de perfis, alteração de permissões para gerenciamento de fan pages e mudanças nas configurações de privacidade. Por se tratar de tarefas secundárias, muitas vezes não utilizadas por usuários comuns, encontram-se numa profundidade maior no sistema, gerando situações de confusão e de erros de acesso. De uma forma geral, esses problemas não prejudicam a eficiência e a usabilidade da rede social.

A prevenção de erros é um ponto importante para quaisquer redes sociais, porque, se elas tiverem um sistema eficiente nesse sentido, impedindo falhas, sempre que possível, darão segurança ao usuário, a ponto de deixá-lo à vontade para a navegação. Cabe ressaltar a importância da utilização de uma linguagem simples, para que o sistema ajude os usuários a reconhecer, diagnosticar e recuperar-se de erros.

Perguntas como “você tem certeza que deseja excluir este comentário?”, as orientações presentes nos campos de postagem da timeline e a opção do usuário de escolher o que quer publicar de seu perfil pessoal ou da página - nos casos de administradores de fan pages - exemplificam o cuidado do Facebook em evitar que seus usuários cometam erros. Essas precauções se baseiam em um trabalho interno de reconhecimento das situações que mais propiciam erros, a partir das quais serão tomadas medidas preventivas na interface, como alertas diretos e de compreensão imediata sobre a atitude que está sendo tomada.

Em vez de exigir que seus usuários memorizem a posição das funções, o sistema deve apresentar seus objetos, ações e opções de forma visível, incentivando o reconhecimento, no lugar da memorização. Além disso, a estética e o design das redes sociais devem ser minimalistas, evitando informações desnecessárias. Eis, a propósito, um exemplo (Figura 5) de utilização de design minimalista em rede social: 


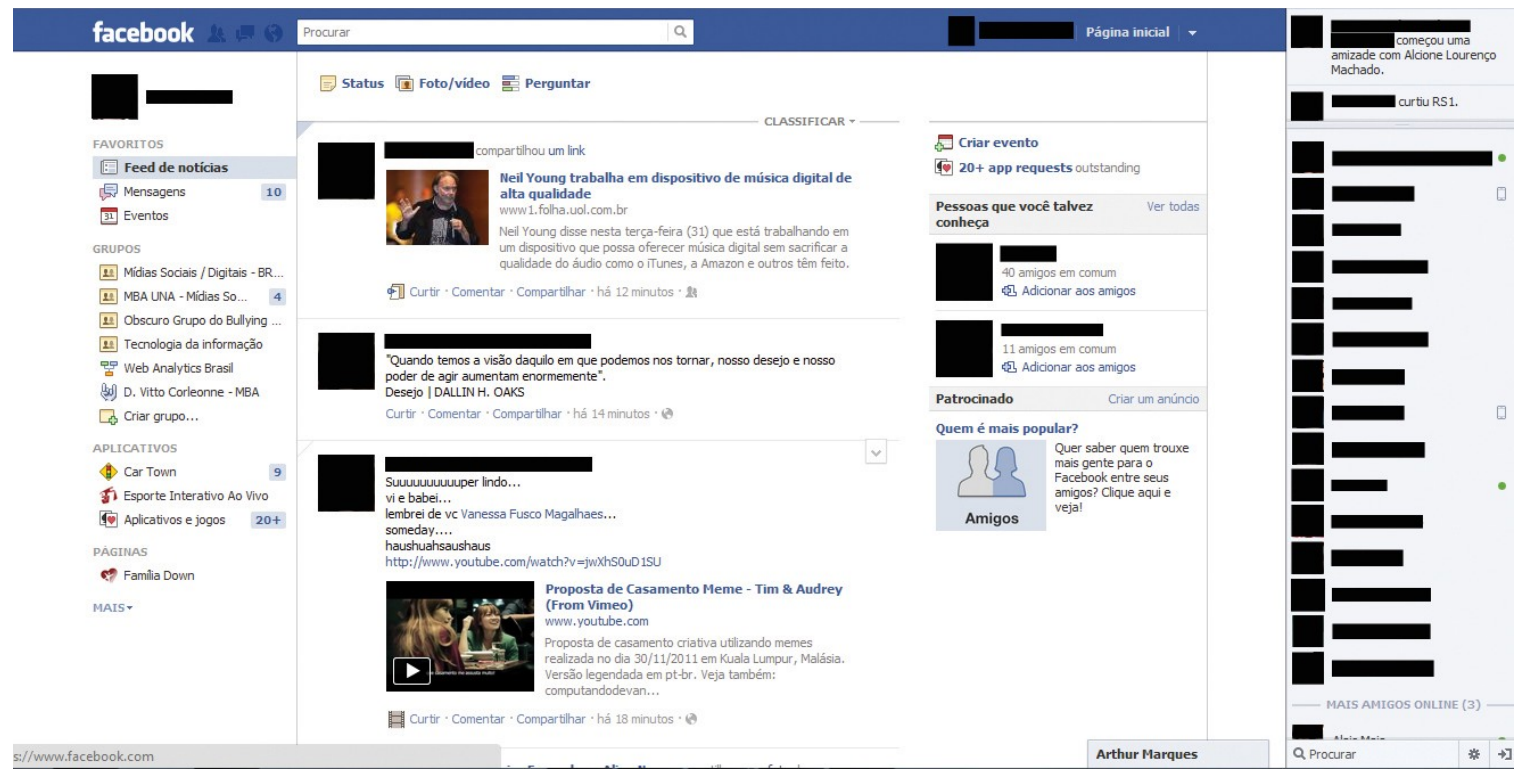

Figura 5: Layout minimalista da timeline (antigo mural) do Facebook Fonte: Facebook (2012)

Esses 2 (dois) critérios são tratados com extrema seriedade pelo Facebook, que adota a "invisibilidade" tanto no design do seu site quanto nos nomes de seus produtos. O design minimalista tenta reproduzir o ambiente real dentro do ambiente virtual, para reduzir as barreiras dos usuários. Para isso, são usadas poucas cores e a iconografia é trabalhada para facilitar o reconhecimento das funções. O maior destaque é dado às imagens, nas capas das fan pages, nas postagens e compartilhamentos das timelines e nos álbuns dentro da aba de fotos. Sua interface também facilita a postagem de links, reconhecendo e formatando em tempo real URL's postadas, ao invés de criar mais um item de menu para tal compartilhamento, o que provocaria uma sobrecarga cognitiva.

Os “produtos” do site também são de fácil identificação: fotos são fotos, vídeos são vídeos, e assim por diante. Essa estratégia fica evidente no depoimento de Christopher Cox, vicepresidente de produto da empresa:

Você pode construir um local com janelas incríveis, ou arcadas realmente lindas, mas isso não significa que as pessoas vão querer sentar nesses locais e ficar por lá. (...) O problema ou desafio que enfrentamos ao criar produtos on-line é que a invisibilidade das tarefas é o que as faz confortáveis para as pessoas (JANA, 2011).

Os 2 (dois) últimos critérios técnicos importantes para se garantir a usabilidade nas redes sociais são flexibilidade e eficiência de uso e ajuda e documentação. $O$ primeiro resgata $o$ conceito de "invisibilidade", para tornar dinâmicas e sem barreiras as ações do usuário, seja qual for a sua experiência. O segundo almeja o cenário ideal em que um software seja intuitivo a ponto de seu usuário não precisar de ajuda ou documentação e, caso precise, que eles sejam obtidos facilmente, on-line.

O Facebook tem boa documentação; entretanto, em alguns momentos é difícil vasculhála, até mesmo pelo grau de complexidade e da profundidade em que a informação está na navegação. Por fim, o site se mostra muito flexível e tem usabilidade fácil, que é garantida pela 
utilização de atalhos, abreviações, funções de retorno em sistemas de hipertexto (como o nome no campo usuário) e a possibilidade de utilizar o clique duplo em alguns comandos.

\section{CONCLUSÃO}

As redes sociais levaram a interatividade e a cibercultura ao estado de plenitude, mudando as dinâmicas dos negócios, do ambiente acadêmico, da construção dos ciclos de amizades e da comunicação como um todo. Isso só aconteceu porque elas têm sido desenvolvidas com base nas necessidades dos usuários, e não apenas nas tecnologias disponíveis, aliando funcionalidade e beleza.

Após a análise da aplicação do design no contexto das redes sociais, verifica-se que essa disciplina é fundamental para garantir o aumento de usuários e da interação. Foi constatado que isso ocorre como consequência do emprego adequado de seus conceitos na construção de sites cujas interfaces sejam atrativas, leves e fáceis de usar, a ponto de eliminar as barreiras existentes na comunicação por meio de plataformas digitais. $\mathrm{O}$ design aliado à usabilidade garante projetos mais eficazes, cujo resultado é um ambiente agradável e propenso à interação e à colaboração.

O estudo que usou o Facebook como amostra da aplicação do design nas redes sociais apontou bons exemplos a serem seguidos, assim como falhas a serem corrigidas, que podem estar presentes em outras redes. Mostrou a importância de se trabalhar a simplicidade dos elementos do layout - tanto os visuais quanto nas nomenclaturas -, de dar respostas breves, oferecer gerenciamento rápido, boa documentação, controle sobre tarefas e direcionamento das informações de forma linear e clara. Seus exemplos servem para outras redes sociais, genéricas ou específicas, que queiram aumentar o número de usuários e satisfazer as necessidades dos mesmos.

Da mesma forma, as redes sociais devem estar atentas aos erros e inconsistências apresentados, para não comprometer a experiência do usuário. No exemplo do Facebook, vemos que ele é, em muitos casos, unilateral em relação aos dados do usuário, retendo para si o controle sobre eles. Devido a isso, notamos complexidade na busca de informações documentadas pelo site, na visualização e gestão de atualizações e na edição de alguns tipos de compartilhamentos. Também apresenta pontos negativos no menu, que dificultam a localização de algumas ferramentas de gerenciamento e as mudanças nas configurações da conta. Situações que merecem atenção, estudo e reestruturação, o que o Facebook e outras redes sociais têm mostrado bastante flexibilidade e disposição para fazer.

Ainda não é possível prever até que ponto as redes sociais poderão crescer, mas é certo que o usuário continuará tendo o papel central no desenvolvimento delas, por meio do feedback de suas experiências. E o elemento que aproximará redes e usuários e trabalhará em prol da interação entre essas duas partes será o design.

\section{REFERÊNCIAS}

ALTERMANN, D. Qual a diferença entre redes sociais e mídias sociais? In: Midiatisno [blog], 06 set. 2010. Disponível em: <http://www.midiatismo.com.br/comunicacao-digital/qual-a-diferenca- 
entre-redes-sociais-e-midias-sociais>. Acesso em: 20 nov. 2011.

ARNOLD, T. C. Além da interação homem-computador: O Design de Interação, seus processos e metas, em busca da satisfação do usuário final. 2010. Disponível em: $<$ http://www.designemartigos.com.br/wp-content/uploads/2010/07/design de interacao.pdf $>$. Acesso em: 19 dez. 2011.

BARANAUSKAS, M. C. C.; HORNUNG, H.; MARTINS, M. C.. Design Socialmente Responsável: Desafios de Interface de Usuário no Contexto Brasileiro. In: SEMISH, SEMINÁRIO INTEGRADO DE SOFTWARE HARDWARE, 35. / CONGRESSO DA SBC SOCIEDADE BRASILEIRA DE COMPUTAÇÃO, 28., 2008, Belém. Anais..., Belém: SBC, 2008. p. 91-105. Disponível em: < http://www.lbd.dcc.ufmg.br/colecoes/semish/2008/007.pdf>. Acesso em: 15 nov. 2011.

BELTERSEN O. W. Tertiary Artefactness at the Interface. In: FISHWICK, P. (ed). Aesthetic Computing. Cambridge, MA: MIT Press. 2006. p. 357-368.

BOYD, D. B.; ELLISON, N. B. Social Network Sites: Definition, History, and Scholarship. Journal of Computer-Mediated Communication, Indiana University School of Library \& Information Science, Indianápolis, Indiana (E.U.A.), v. 13. n. 1, 2007. Disponível em:

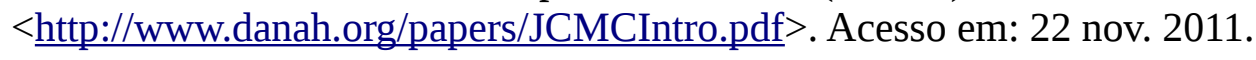

DIAS, Cláudia. Usabilidade na Web: criando portais mais acessíveis. 2. ed. Rio de Janeiro: Atlas Books, 2007.

ELLISON, N. B.; LAMPE, C.; STEINFIELD, C. Feature Social Network Sites and Society: Current Trends and Future Possibilities. In: ACM Interactions, v. 16, n. 1, p. 6-9, 2009. Disponível em: <http://dl.acm.org/citation.cfm?doid=1456202.1456204>. Acesso em: 08 jan. 2012.

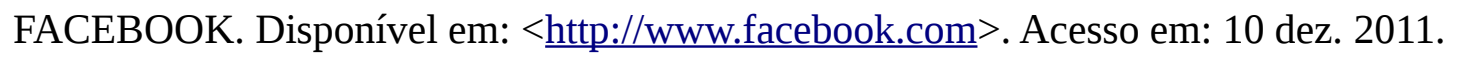

GOOGLE+. Disponível em: <http://www.plus.google.com>. Acesso em: 10 dez. 2011.

GOTTFREDSON, L. Mainstream science on intelligence: an editorial with 52 signatories, history and bibliography. Intelligence, Norwood, v. 24, n. 1, p. 13-23, Special issue 1997. Disponível em: <http://www.nazi.org.uk/ScienceAndAcademia/Gottfredson-MainstreamScienceOnIntelligenceAnEditorialWith52Signatories.pdf>. Acesso em: 23 mai. 2013.

JANA, R. Facebook's Design Strategy: A Status Update. Design Mind. 2011. Disponível em: $<\underline{\text { http://designmind.frogdesign.com/articles/facebook-s-design-strategy-a-status- }}$ update.html\#/images/dm/issues/the-connective-issue/articles/facebook/facebook-slide-1.jpg>. Acesso em: 10 jan. 2012.

LÉVY, P. A Inteligência Coletiva: Por uma antropologia do ciberespaço. Tradução de Luiz Paulo Rouanet. São Paulo: Loyola, 1998. 212 p.

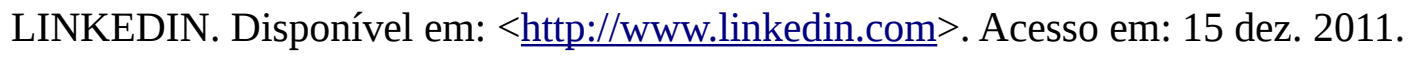


LONG, N. Development Sociology: actor perspectives. London and New York: Routledge, 2001. $293 \mathrm{p}$.

MCCARTHY, J.; WRIGHT, P. Technology as experience. Cambridge, MA: MIT Press, 2004.

MISLOV, A.; MARCON, M.; GUMMADI, K. P.; DRUSCHEL, P.; BHATTACHARJEE, B. Measurement and Analysis of Online Social Networks. In: ACM SIGCOMM CONFERENCE ON INTERNET MEASUREMENT, 7., 2007, San Diego, Califórnia (E.U.A.). Proceedings... San Diego, Califórnia (E.U.A.): ACM SIGCOMM; USENIX, 2007. p. 29-42. Disponível em: $<$ http://conferences.sigcomm.org/imc/2007/papers/imc170.pdf > . Acesso em: 20 dez. 2011.

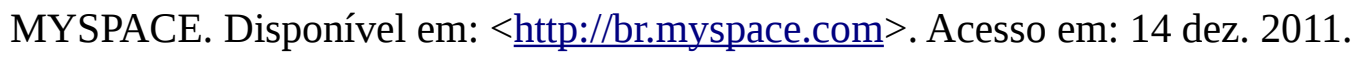

NIELSEN, J. Ten Usability Heuristics. 2001. Disponível em: <http://www.useit.com/papers/heuristic/heuristic list.html>. Acesso em: 24 dez. 2011.

NIELSEN COMPANY. Global Faces and Networked Places: a Nielsen Report on Social Networking's New Global Footprint. 2009. Disponível em: $<$ http://blog.nielsen.com/nielsenwire/wp-content/uploads/2009/03/nielsen globalfaces mar09.pdf $>$. Acesso em: 25 nov. 2011.

NIELSEN \& NM INCITE. State of the Media: The Social Media Report - q3, 2011. 2011. 13 p. Disponível em: $\quad$ http://cn.nielsen.com/documents/Nielsen-Social-MediaReport FINAL 090911.pdf >. Acesso em: 10 dez. 2011.

NORMAN, D. Emotion and design: Attractive things work better. Interactions Magazine, ix (4). 2002. p. 36-42.

NORMAN, D. Emotional design: why we love (or hate) everyday things. NewYork: Basic Books, 2004.

NORMAN, D. O design do dia-a-dia. Tradução de Ana Deiró. São Paulo: Rocco, 2006.

OLIVEIRA, A. L. B. A melhor interação entre o homem e a máquina. In: Revista Custo Brasil. Rio de Janeiro, ano 4, n. 21, p. 36-40, 2009. Disponível em: <http://www.revistacustobrasil.com.br/21/pdf/04.pdf > . Acesso em: 25 nov. 2011.

PREECE, J.; ROGERS, Y.; SHARP, H. Design de Interação: Além da Interação homem computador. Tradução de Viviane Possamai. Porto Alegre: Bookman, 2005. 548 p.

RECUERO, R. Redes Sociais na Internet: considerações iniciais. 2004. 15 p. Disponível em: $<$ http://www.bocc.ubi.pt/pag/recuero-raquel-redes-sociais-na-internet.pdf $>$. Acesso em: $10 \mathrm{fev}$. 2012.

REE, M.; EARLES, J. Predicting training success: not much more than g. Personnel Psychology, Durham, v. 44, n. 2, p. 321-332. Summer 1991. Disponível em: $<$ http://onlinelibrary.wiley.com/doi/10.1111/j.1744-6570.1991.tb00961.x/abstract>. Acesso em: 24 mai. 2013. 
SANTANA, V. F.; MELO-SOLARTE, D. S.; NERIS, V. P. A.; MIRANDA, L. C. de; BARANAUSKAS, M. C. C. Redes Sociais Online: Desafios e Possibilidades para o Contexto Brasileiro. In: SEMINÁRIO INTEGRADO DE SOFTWARE E HARDWARE (SEMISH), 36. / CONGRESSO DA SOCIEDADE BRASILEIRA DE COMPUTAÇÃO (CSBC), 29. 2009, Bento Gonçalves. Anais..., Bento Gonçalves: Universidade Federal do Rio Grande do Sul, 2009. p. 339353. Disponível em: <http://metropoa.inf.ufrgs.br/anais/pdf/semish/st04 04.pdf>. Acesso em: 12 nov. 2011.

SKOOB. [página de internet]. Disponível em: <http://www.skoob.com.br/>. Acesso em: 12 dez. 2011.

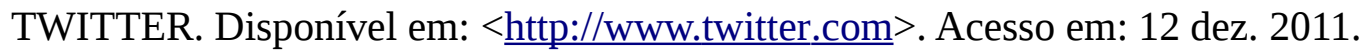

VAN AMSTEL, F. Design de redes sociais baseado em psicologia e sociologia. Minicurso de Design de Redes Sociais. Instituto Faber-Ludens de Design de Interação. 2011. Disponível em: <http://www.slideshare.net/usabilidoido/design-redes-sociais?from=ss embed $>$. Acesso em 02 nov. 2011.

WARZEL, C. What People Are Actually Doing On The Internet In 2013. BuzzFeed. 02 mai. 2013. Disponível em: <http://www.buzzfeed.com/charliewarzel/what-people-are-actually-doing-on-theinternet-in-2013>. Acesso em: 24 mai. 2013. 
i Ree e Earles (1991) relacionam o termo com a capacidade individual de apreender e processar informação. Já Gottfredson (1997), define que ele envolve a capacidade de raciocínio, planejamento, resolução de problemas, pensamento abstrato e aprendizagem rápida a partir da experiência.

ii Raquel Recuero. 2008. Disponível em: $<$ http://www.raquelrecuero.com.br/arquivos/imagens/2rede.jpg $>$. Acesso em: $10 / 01 / 2012$.

iii Twitter. 2012. Disponível em: <http://www.twitter.com/brunocssantos $>$. Acesso em: 10/01/2012.

iv Skoob. 2012. Disponível em: <http://www.skoob.com.br/usuario/188567-brunocssantos $>$. Acesso em: 10/01/2012.

v Conceito proposto por LÉVY (1998), caracterizado por um pensamento sustentado por conexões sociais viáveis por meio das redes abertas de computação na internet.

vi A cultura de massa é uma cultura fabricada pela ideologia, que tenta se apresentar como sendo a própria cultura.

vii Teoria que estuda o fenômeno de empresas de internet que conseguem faturar, com produtos de nicho de mercado, tanto quanto ou até mais que com os tradicionais “arrasa-quarteirão".

viii Termo criado para designar as mudanças que podem acontecer em uma sociedade diante de sua fusão com elementos culturais externos.

ix Termo utilizado para denominar produções culturais voltadas para o consumo massificado.

x Segundo WARZEL (2013), a pesquisa publicada em maio de 2013, listou os 30 (trinta) sites com maior visitação mensal, dos quais 14 (quatorze) eram redes sociais.

xi Facebook. 2012. Disponível em: <http://www.facebook.com/cocacola> . Acesso em: 28 mar. 2012.

xii Facebook. 2012. Disponível em: $<\underline{\text { https://www.facebook.com/brunocssantos?ref }=t n ~ t n m n \& ~ a d t=10}>$. Acesso em: 20 jan. 2012. 